\title{
Severing idiosyncratic case from the lexical verb in Uyghur-Chinese code switching
}

\author{
Alexander Sugar \& Zaoreguli Abulimiti*
}

\begin{abstract}
This paper discusses case marking in mixed verbs in Uyghur-Chinese code switching, where a lexical verb from Mandarin Chinese is combined with a light verb from Uyghur. In mixed verbs containing a Chinese verb whose Uyghur translational equivalent idiosyncratically selects a dative object, the mixed verb also selects a dative object. We analyze this fact by proposing that dative arguments are introduced by an applicative head (Cuervo 2003) whose presence is required by a $v$ head selecting for certain types of roots along the lines of Merchant (2018).
\end{abstract}

Keywords. lexical case; idiosyncratic case; datives; code switching; Uyghur; Chinese; syntax; morphology

1. Introduction. Theories of morphological case generally distinguish between case marking that is the result of some structural configuration and case marking associated with particular verbs (Chomsky 1981, 1986, Marantz 1991, Woolford 2006 inter alia). A longstanding assumption has been that it is possible for lexical verbs themselves to idiosyncratically assign case to their internal argument.

The Turkic language Uyghur shows a clear distinction between structurally determined case and idiosyncratically assigned case. The accusative marker - $n i$ on the object in (1) generally appears on any specific direct object and can be attributed to a structural configuration (either agreement with some functional head or being the lower of two nominals in a domain where case is assigned). However, the objects of certain verbs, like ishen 'to believe' in (2), surface with dative case (glossed as $-g a$ ) rather than accusative.
Men kino-ni
chüshür-di-m.
1SG movie-ACC download-PST-1SG
'I downloaded the movie.' (uig)
Men siz-ga
ishin-i-men.
$1 \mathrm{SG}$ 2SG.FORM-DAT believe-NPST-1SG
'I believe you.' (uig)

Woolford (2006) famously demonstrated that non-structural case (i.e. not nominative or accusative in a language like Uyghur) can be divided into two types: lexical and inherent case. Lexical case is unpredictable and assigned by a specific lexical item. Inherent case, on the other hand, is associated with certain theta role positions and assigned by light verb (little $v$ ) heads. This division is quoted in (3).

(3) Two types of nonstructural Case (Woolford 2006: 112)

Lexical Case: Idiosyncratic, lexically selected Case

Inherent Case: Case inherently associated with certain [theta] positions

*Thank you to the audience of the 93rd Annual Meeting of the Linguistic Society of America for helpful questions and suggestions, and to Edith Aldridge for helpful discussion of some of the data presented here. All errors are our own. Authors: Alexander Sugar, University of Washington (sugara@u.washington.edu) \& Zaoreguli Abulimiti, Shaanxi Normal University (zohra2009@163.com). 
Crucially, Woolford claims that themes may take lexical case but not inherent case. Her generalization is given in (4).

(4) Complementary distribution of lexical and inherent Case (woolford 2006: 115)

Lexical Case may occur on themes/internal arguments, but not on external arguments, or on (shifted) DP goal arguments.

Inherent Case may occur on external arguments and on (shifted) DP goal arguments, but not on themes/internal arguments.

According to Woolford's generalization, then, dative case realized on themes in Uyghur sentences like (2) must be assigned by the lexical verb itself.

This paper will provide evidence from code switching at the verb (phrase) level between Uyghur and Chinese that the dative marker in sentences like (2) must come from a source other than the lexical verb itself. The crucial data are sentences in which a Chinese verb (phrase) is embedded in what otherwise looks like an Uyghur sentence. Curiously, when the Chinese verb is the translational equivalent of an Uyghur verb that would idiosyncratically assign dative case, the object of the mixed verb is also assigned dative case. In light of this data, we will suggest that dative objects are introduced by an applicative head whose presence is conditioned by a light verb that is sensitive to semantic information provided by the verb root.

This article is organized as follows. Section 2 introduces some key properties of Uyghur and Chinese grammar. Section 3 gives special attention to what types of nominals may be assigned morphological dative case in Uyghur. In section 4, we introduce the construction we call the 'mixed verb' as a form of code switching at the verbal level. The core data will be presented in section 5, where we show that certain Chinese verbs appear to idiosyncratically assign dative case when embedded in a mixed verb, leading us to the conclusion that dative case is not being assigned directly by a lexical head. Section 6 argues against an analysis that the Chinese verbs seen in section 5 are just loanwords inserted to match the underlying features of an Uyghur root. Section 7 presents our proposal, that dative case is assigned to themes by an applicative head required by an Uyghur light verb that selects certain classes of roots. In section 8 we discuss two putative exceptions to the pattern presented in section 5, and section 9 concludes.

\section{Chinese and Uyghur morphoyntax.}

2.1 CHINESE BASICS. By 'Chinese' here we mean the common variety of Mandarin (aka pŭtōnghuà) widely spoken by residents of the Xinjiang Uyghur Autonomous Region in the Northwest corner of the People's Republic of China. Chinese is an analytic language canonically exhibiting subject-verb-object (SVO) word order.

$$
\begin{aligned}
& \text { Wŏ xiàzăi-le zhè-bù diànyĭng. } \\
& 1 \mathrm{SG} \text { download-PFV DEM-CL movie } \\
& \text { 'I downloaded this movie.' (cmn) }
\end{aligned}
$$

There are also verbs, many expressing some sort of psychological meaning, that select preverbal objects marked with a preposition (like duì in (6)). 
All core examples to be presented in section 5 will involve Chinese verbs whose postverbal internal arguments are unmarked. For the purposes of this article, we consider Chinese to be a language lacking morphological case in its canonical $\mathrm{VO}$ word order. The next section shows that this characteristic directly contrasts with Uyghur grammar.

3.1 UYGHUR BASICS. Uyghur is an Altaic language spoken by at least ten million speakers, most of whom live in the Xinjiang Uyghur Autonomous Region of the People's Republic of China. Unlike Chinese, Uyghur canonically exhibits subject-object-verb (SOV) word order, the subject being optional. It is an agglutinative language in which words can host some prefixes and many suffixes. The verb chüshür 'to download' in (7) takes suffixes marking past tense and agreement with the subject. Uyghur shows nominative-accusative alignment, with nominative case not overtly marked. As demonstrated by the contrast between (1) and (7), only specific objects are overtly marked for accusative case.

(Men) kino chüshür-di-m.

(1SG) movie download-PST-1SG

'I downloaded a movie.' (uig)

When a transitive verb is passivized, the accusative object becomes the nominative subject.

$\mathrm{Bu}$ kino chüshür-il-di-0.

DEM movie download-PASS-PST-3

'This movie was downloaded.'

When a transitive verb is causativized, the causee takes dative case. This is one piece of evidence that Uyghur observes a constraint restricting the number of accusative arguments in a clause to one, similar to the 'double-o constraint' of Japanese (Harada 1973).
Abliz Tursun-ga/*ni
chay(-ni) ich-guz-di-0.
Abliz Tursun-DAT/*ACC tea(-ACC) drink-CAUS-PST-3
"Abliz made Tursun drink (the) tea." (uig)

3. Dative case. Dative case appears on a variety of arguments in Uyghur. As just shown in (9), the causee of a typical causative construction is realized with dative case. Dative case is also assigned to goal arguments of directional predicates (10) and indirect objects (often goals as well) of ditransitive verbs (11).

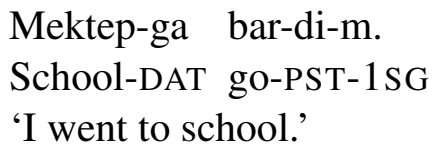

Applied objects, made available by use of the verb ber 'to give', also take dative case. 
Siz-ga qoghun al-(i)p ber-ay.

2SG.FORM-DAT melon get-(I)P give-1SG.IMP

'Let me get a melon for you.' (uig) (Engesæth et al 2009: 240)

Of particular interest in this article is that there are certain classes of verbs whose theme objects take dative rather than accusative case. The first class includes many psychological predicates (Aihemaiti 2011). Notice that while languages like Spanish assign dative case to experiencers (Cuervo 2003), in Uyghur it is the theme that is assigned dative case, and the subject is nominative.
Men putbol-ga qiziq-i-men.
$1 \mathrm{SG}$ soccer-DAT interest-NPST-1SG
'I'm interested in soccer.' (uig)

The second class of verbs which take dative theme arguments have the meaning 'to look after, care for'.
Ular bala-i-ga
qara-iwat-i-du.
3PL child-3.POSS-DAT look.after-PROG-NPST-3
'They are looking after their child.' (uig)

Finally, there is a small handful of other verbs whose themes are realized with dative case which cannot group into one coherent class. One example is mas kel 'to be suitable'.
U qiz siz-ga
mas kel-ma-i-du-iken.
DEM girl 2SG.FORM-DAT suited come-NEG-NPST-3-EVID

'I don't think that girl suits you.'

Unlike accusative themes, dative themes cannot be promoted to subject position under passivization. They cannot receive nominative case, do not trigger agreement on the verb, and cannot be the sole non-adjunct argument in a sentence.

$$
\begin{array}{lll}
* \text { Biz(-ga) } & \text { (mektep terep-i-din) ghemxorluq qil-in-iwat-i-imiz. } \\
\text { 1PL-(DAT) } & \text { (school side-3.POSS-ABL) care do-PASS-PROG-NPST-1PL } \\
\text { Intended: 'We are being looked after (by the school).' }
\end{array}
$$

Having established the crucial properties of Chinese and Uyghur morphosyntax for our purposes, we next turn our attention to code switching between the two language.

\section{Code switching and mixed verbs.}

4.1 UYGHUR-CHINESE CODE SWITCHING. Code switching can be roughly defined as the mixing of two or more languages in discourse. In this article we limit our attention to the mixing of two or more languages within a sentence. One key difference between code switching and lexical borrowing has to do with speech community: while monolingual speakers may use loan words without even being aware of their origin, code switching is only practiced by multilingual speakers in interactions in which they can be sure that their interlocutor also has the multilingual competence to understand them.

Younger Uyghur speakers are more likely than older generations to be highly competent in 
Chinese due to its increasing value in education and the workplace. It is thus unsurprising that code switching between Uyghur and Chinese is mostly limited to speakers born in the last few decades (Zaoreguli 2009). Code switching can happen between phrases or even individual words. The most common type of foreign word to be used in code switching is a noun, but speakers can also use verbs foreign verbs or verb phrases in their code switching (Wohlgemuth 2009). The next subsection introduces this construction.

4.2 MIXED VERBS. Mixed verbs in Uyghur-Chinese code pair a light verb from Uyghur with a lexical verb from Chinese). ${ }^{2}$ For example, in (20) the Chinese verb xiazai 'to download' is followed by the Uyghur light verb qil 'do'. ${ }^{3}$ While the Chinese verb is bare, the Uyghur light verb inflects for tense and person like any Uyghur verb is required to do in a finite context. ${ }^{4}$

$$
\begin{aligned}
& \mathrm{Bu} \text { kino-ni xiazai qil-di-m. } \\
& \text { DEM movie-ACC download do-PST-1SG } \\
& \text { 'I downloaded this movie.' }
\end{aligned}
$$

While the light verb do was used to accomodate an agentive predicate ('to download') in (20). The light verb bol 'to be(come)' is used when the subject is non-agentive, as is the case in (21).

$$
\begin{aligned}
& \text { Men qi-bing bol-di-m. } \\
& 1 \mathrm{SG} \text { angry-sick be-PST-1SG } \\
& \text { 'I became furious.' }
\end{aligned}
$$

In both (20) and (21), the verb was Chinese but the internal argument was Uyghur. It is also possible for the verb and its internal argument to be Chinese. As demonstrated in (22), however, the Chinese object can still precede the verb according to Uyghur OV word order and take a Uyghur case marker (like the accusative case marker - ni).

\footnotetext{
${ }^{2}$ We follow Lakshmanan et al (2016) in referring to this construction as a 'mixed verb' because we consider this construction to be unique to code switching. The term 'mixed verb' avoids confusion with light verb constructions which are also used to verbalize older loan words, as shown in example (17) where qil verbalizes an Arabic loan.

(17) $\mathrm{Bu}$ qiyin ish-ni hel qil-di-m.

DEM difficult matter-ACC solved do-PST-1SG

"I solved this difficult matter." (uig) (www.uycnr.com/jy)

See Sugar (2017) for discussion of the differences between mixed verbs and monolingual light verb constructions. One difference is that while the verb in a light verb construction may be nominalized, the Chinese verb does not show nominalized behavior in mixed verbs. Compare the presence of an accusative case marker on the verb hapsek 'table sharing' of alleged Chinese origin when combined with a Korean light verb in (18) with the inability of the Chinese verb saomiao 'to scan' to take accusative case in the mixed verb in (19). Also notice the availability of accusative case for the object of the mixed verb in (20).

(18) Kibo-nun Dana-wa hapsek-ul hayss-ta

Kibo-TOP Dana-with table.sharing-ACC do.PST-DECL

"Kibo shared a table with Dana." (kor) (shim2016mixed: 8)

${ }^{3}$ All Chinese items in code switching are glossed in italics.

${ }^{4}$ Chinese tones are unmarked in the glosses of mixed verbs because Uyghur speakers vary in their degree of acquisition of Chinese tone (Zhu 2007).
} 
Mima-ni chongxin she-le qil-sa-m bol-gudek.

Password-ACC newly set-LE do-COND-1SG be.good-MOD

'I should probably set a new password.'

While the OV word order of Uyghur is more common in the mixed verb, it is also possible for Chinese VO word order to be preserved in the mixed verb. Only in OV word order will the Chinese object take Uyghur case marking.

$\mathrm{U}$ men-ga $f a$ duanxin qil-di-0.

3SG 1SG-DAT send text.message do-PST-3

'(S)he sent me a text message.'

$\mathrm{U}$ men-ga duanxin-ni fa-le qil-di-0.

3SG 1SG-DAT text.message-ACC send-LE do-PST-3

'(S)he sent me a text message.'

In (24), the object duanxin 'text message' takes the -ni accusative marker typical of objects in Uyghur grammar. The next section introduces examples in which the object of a mixed verb unexpectedly receives dative case.

5. Dative case in mixed verbs. The majority of mixed verbs show the same nomimative-accusative alignment pattern of monolingual Uyghur grammar. Thus the object of the mixed verb in (20) receives accusative case just as it does in the monolingual Uyghur sentence (25).
Men kino-ni chüshür-di-m.
$1 \mathrm{SG}$ movie-ACC download-PST-1SG
'I downloaded the movie.' (uig)

Curiously, when the Chinese translational equivalent of one of the Uyghur verbs whose theme object idiosyncratically receives dative case is used in a mixed verb, the object receives the same dative case marking from the mixed verb. For example, the verb tizimlat 'to enlist' in Uyghur takes a dative object as shown in (26).
Men memurluq-ga tizim-la-t-di-m.
$1 \mathrm{SG}$ civil.service-DAT list-VBLZ-CAUS-PST-1SG
'I enlisted in the civil service.' (uig)

As (27) shows, the Chinese verb meaning 'to enlist', bào, does not require any idiosyncratic marking of its object.
Wŏ bào-le gōngwùyuán.
1SG enlist-PFV civil.servant
'I enlisted as a civil servant.' (cmn)

When the Chinese verb bao is used in a mixed verb, however, then the object takes dative case as if the Uyghur translational equivalent were still used. 
Men gongwuyuan-ga bao-le qil-di-m.

1SG civil.servant-DAT enlist-LE do-PST-1SG

'I enlisted as a civil servant.'

We found in our corpus of 488 mixed verbs that for any Uyghur verb whose object takes dative case, if its Chinese translational equivalent can be used in a mixed verb, then the object of the mixed verb takes dative case as well. We consider a Chinese word to be a 'translational equivalent' of an Uyghur word if the Chinese word is among the results of the entry of the Uyghur word in an Uyghur-Chinese dictionary, or if both the Chinese and Uyghur word can translate to the same English word in a Chinese-English or Uyghur-English dictionary, respectively. We state our finding as the Mixed Verb Case Generalization.

(29) Mixed Verb Case Generalization: When an Uyghur verb assigns idiosyncratic case to its internal argument, this case assignment is preserved in a mixed verb containing its Chinese translational equivalent.

Table 2 lists the Chinese verbs we have found in mixed verb examples that seemingly assign dative case like their Uyghur translational equivalents. Examples of each verb are ommitted here in the interest of brevity.

\begin{tabular}{|c|c|c|}
\hline English & Uyghur & Chinese \\
\hline To enlist & tizimlat & 报 bao \\
\hline To suit & mas kel & 配 pei \\
\hline \multirow{2}{*}{ To look after, care for } & qara & \multirow{2}{*}{ 照顾 zhaogu } \\
\cline { 2 - 2 } & etiwar qil & \\
\cline { 2 - 3 } Psych preds: to envy, \\
$\begin{array}{c}\text { admire, worship, } \\
\text { appreciate, care about }\end{array}$ & $\begin{array}{c}\text { ghemorluq qil } \\
\text { heset qil, hewes qil, qayil } \\
\text { bol, köyün }\end{array}$ & $\begin{array}{c}\text { 嫲妒 jidu, 羡慕 xianmu, 佩服 } \\
\text { peifu, 崇拜 chongbai, 欣赏 } \\
\text { xinshang }\end{array}$ \\
\hline To threaten & texdit sal & 威胁 weixie \\
\hline
\end{tabular}

Table 2: Chinese translational equivalents used in mixed verbs of Uyghur verbs that idiosyncratically assign dative case

There are two potential analyses of the above data. One analysis is that mixed verb examples are not instances of code switching, but instead the Chinese verbs are realizations of the same abstract features present in their Uyghur counterparts. The second analysis is that dative case in the above examples is not assigned by lexical verbs, but by some functional head under certain conditions. We will evaluate and reject the first analysis in the next section before developing the latter in section 8 .

6. Potential explanation: Loanword vocabulary item insertion. One explanation of the data from section 5 would be to say that there is no code switching in these sentences. That is, perhaps the Chinese verbs are vocabulary items available to Uyghur speakers to match the features of abstract roots under a Distributed Morphology Model (Halle \& Marantz 1993) along with their Uyghur translational equivalents. This explanation amounts to saying that the Chinese verbs are loanwords, part of Uyghur speakers' native vocabulary. 
Support for this explanation comes from the fact that Uyghur light verbs are indeed used to verbalize older loanwords, mainly from Persian and Arabic, which are now regarded as regular members of the Uyghur lexicon. An example of this construction was given in example (17) from footnote 2 .

We reject this explanation. Recall first that mixed verb constructions with Chinese verbs are only used by younger Uyghurs with bilingual competence, a hallmark of code switching. Second, Chinese verbs (and other Chinese vocabulary items) are usually pronounced with some degree of tone, indicating a lack of full integration into Uyghur phonology. Third, internal arguments as well as adverbials can come from Chinese as well (recall example (22)), and it is even possible for the mixed verb construction to preserve Chinese VO word order (recall example (23)), suggesting that the mixed verb may contain a Chinese verb phrase rather than just a verb.

Here we provide three more reasons for believing there is some level of Chinese grammar still present in mixed verbs.

7.1 Chinese Argument Selection. Despite case marking patterns appearing to follow Uyghur grammar, the Chinese verb in a mixed verb still retains its argument selection ability. For example, the Chinese verb dăzhé 'to discount' selects a discounted item as its internal argument in (30). The Uyghur verb for 'discount', chüshür, on the other hand, selects the price of a discounted item as its internal argument in (31).

Zhè-jiàn yîfú dăzhé-le.

DEM-CL clothing discount-PFV

'This clothing is on sale (discounted).' (cmn)
Kiyim-lar-ning baha-i-ni chüsh-ur-ptu-0.
Clothing-PL-GEN price-3.POSS-ACC lower-CAUS-PST-3
'(They) lowered the price of those clothes.' (uig)

When dazhe is used in a mixed verb in (32), it still selects the discounted item rather than the price as its internal argument.
Kiyim-lar-ni/*baha-si-ni
dazhe qil-ptu-0.
Clothing-PL-ACC/*price-3.POSS-ACC discount do-PST-3
'(They) discounted these clothes.'

The fact that the mixed verb selects the object required by the Chinese verb indicates that it is not composed of all the same features as its Uyghur translational equivalent.

7.2 Causative Meaning Preservation. Certain Chinese verbs are capable of expressing a causative meaning without the addition of overt causative morphology when the causee argument is covert. For example, the verb xī̄ 'to repair' can be used to mean either that the speaker is doing the repair work or that some unnamed third party will do the repair work. 


$$
\text { Wŏ jīntiān xiū diànnăo. }
$$

$1 \mathrm{SG}$ today repair computer

'I'm going to repair my computer today.'

'I'm going to have my computer repaired today.' $(\mathrm{cmn})$

The optional causative meaning captured by the second translation of (33) cannot be expressed in Uyghur without an overt causative suffix.
Bügün kompyuter-ni rémont qil*(-dur)-i-men.
Today computer-ACC repair do*(-CAUS)-NPST-1SG
'I'm going to have my computer repaired today.' (uig)

When the Chinese verb $x i u$ is used in a mixed verb, it is possible to express a causative meaning without a causative suffix on the Uyghur light verb. The causative suffix is optional.
Bügün kompyuter-ni xiu-le qil(-dur)-i-men.
Today computer-ACC repair-LE do(-CAUS)-NPST-1SG
'I'm going to have my computer repaired today.'

Sugar and Zaoreguli (2018) argue that the optionality of the causative suffix in examples like (35) is due to the Uyghur light verb having the option of selecting a Chinese $v \mathrm{P}$ headed by a null causative morpheme. The significance for this article is that there is evidence of Chinese syntactic structure being embedded in the mixed verb, which also disfavors a vocabulary insertion analysis.

7.3 PROSODICALLY CONDITIONED le INSERTION. Our final argument in favor of mixed being instances of code switching has to do with the presence of the le particle in mixed verbs. Much ink has been spilled on the function of $l e$ in monolingual Chinese, but it is generally known to encode something close to perfective aspect (Chao 1965, Li and Thompson 1981, Klein et al. 2000 inter alia). This is not the case in mixed verbs. $L e$ is required in some mixed verbs in clearly non-perfective contexts like (36), and disallowed in some mixed verbs in clearly perfective contexts like (37).

Zhu-yuan shouxu-ni ne-da ban*(-le) qil-i-miz?

Stay-hospital paperwork-ACC where-LOC do*(-LE) do-NPST-1PL

'Where can we take care of the hospital paperwork?'

$$
\begin{aligned}
& \text { Shoucang(-*le) } \\
& \text { Store(-*le) do-Bal-di-m. } \\
& \text { 'I stored it for myself.' }
\end{aligned}
$$

The generalization found in Zaoreguli and Sugar (under review) is that le is required on every monosyllabic Chinese verb and disallowed on any disyllabic verb in a mixed verb, regardless of aspectual context. Interestingly, this requirement is not imposed on verbs from other languages when used in Uyghur mixed verbs or light verb constructions. (38) is an example with a monosyllabic verb from Uyghur-English code switching. 


$$
\begin{aligned}
& \text { Mawu pizza-ni share qil-ayli. } \\
& \text { DEM pizza-ACC share do-1 PL.IMP } \\
& \text { 'Let's share this pizza!' (uig-eng) }
\end{aligned}
$$

Shih (1986), Feng (2001), Duanmu $(2007,2012)$ among others have argued that Chinese has a dispreference for monosyllabic words under stress. Zaoreguli and Sugar (under review) argue that the $l e$ requirement has to do with word order shifting nuclear stress to the lexical verb based on syntactic embedding (Kahnemuyipour 2009, Ahn 2014 inter alia). The crucial takeaway here is that a Chinese prosodic constraint can be active in the mixed verb, suggesting that there is a real switch from the grammar of Uyghur to that of Chinese.

7. Towards an analysis: Dative assigned by high applicative. An analysis dispensing with case assignment directly by a lexical head must answer two questions: 1) how is idiosyncatic case assigned?; and 2) how does does the choice of lexical verb condition case assignment? We briefly touch upon each question in turn.

First, we follow Cuervo (2003) in assuming that dative arguments are introduced by applicative heads. Two main varieties of applicative heads have been posited in the literature: low applicative heads, which relate an internal argument to an applied argument; and high applicative heads, which relates an event to an applied argument. Low applicatives select DP as a complement, while high applicatives select $v \mathrm{P}$. Since the examples of interest in this article contain only one internal argument (the dative), the applicative head licensing dative themes in Uyghur must be a high applicative. Indeed, if we posited a low applicative, it would have to appear within the Chinese VP, which does not assign dative case. The high applicative phrase, however, is the complement of the Uyghur Voice head, and selects the Uyghur $v \mathrm{P}$ as its complement.

If objects are assigned dative case by an applicative head merged after the Uyghur light verb, then the next question is how the syntax knows to merge an applicative head in the presence of certain lexical verbs. Here we follow an idea proposed by Merchant (2018) that light verb flavors may come with specifications about the type of root meaning they select and the type of preposition qua case they require for the verb's complement. Merchant observes that some English words derived from the same root take different types of prepositional complement depending on word class. The contrast between (39) and (40) illustrates this observation for the root $\sqrt{p r d}$.

(39) She prides herself on/*in/*of her thoroughness.

(40) Her pride in/*on/*of her thoroughness is understandable. (eng) (Merchant 2018: 6)

Merchant accounts for this variation by assuming that categorizing heads ( $v, n$ etc.) both for certain roots and for certain PP complements. The entry of the $v_{i n}$ head which appears in sentences like (39) will look as follows, where CAT denotes to the syntactic category it derives and SEL denotes the roots and preposition it selects. 


$$
\mathrm{V}_{\text {on }}\left[\begin{array}{l}
\operatorname{CAT}[\mathrm{V}] \\
\operatorname{SEL}[<(\bullet \sqrt{P R D} \ldots), \bullet \text { on }>]
\end{array}\right]
$$

(Merchant 2018: 9)

We propose that in a similar fashion, an Uyghur light verb head can select for certain (types of) roots and encode its requirement of a functional head that introduces a dative argument. The default flavor of v/qil may select most roots and not encode a case requirement, ${ }^{5}$ resulting in assignment of dependent/structural accusative case to the object. The qil High ApplP $_{\text {head, on the }}$ other hand, selects for roots with meanings like 'admire' or 'look after' among others, ${ }^{6}$ and bears a feature requiring that dative case be present. We call this feature [-Dat] for the time being, though this system will surely need to be revised. If a high applicative introducing a [+ Dat] argument is not merged to check the [-Dat] feature, the derivation will crash. Based on Merchant's representations, the entry for $q i l_{H i g h A p p l P}$ will look something like (42).

$$
\text { qil }_{\text {High ApplP }}\left[\begin{array}{l}
\text { CAT }[v] \\
\operatorname{SEL}[<(\bullet \sqrt{\text { admire }}, \sqrt{\text { lookafter } . . . ~})> \\
\text { CASE }[- \text { Dat }]
\end{array}\right]
$$

Under this analysis, Chinese and Uyghur roots need not be identical, but they encode the same type of meaning targeted by one flavor of light verb. The fact that the root selected by the light verb may be either Uyghur or Chinese is consistent the minimalist assumption that there are no language-marking features present in the syntax of code switching (MacSwan 2014).

We follow Harley (2014) in assuming that objects can be merged as direct complements of a root. Thus the Chinese verb phrase may either merge with its complement, which will be displaced into the Uyghur portion of the clause where it is assigned case, or an Uyghur object may merge directly as the specifier of a functional head. Putting the above discussion together, we sketch a partial derivation of the former possibility (e.g. (28)) in (43) and the latter possibility (e.g. (44)) in (45).

\footnotetext{
${ }^{5}$ We follow Sugar (2017) in analyzing qil 'do' as an overt $v$ head required in certain contexts including code swithcing.

${ }^{6}$ See Blume (1998) for discussion of how the selection of dative themes may be semantically conditioned by roots.
} 


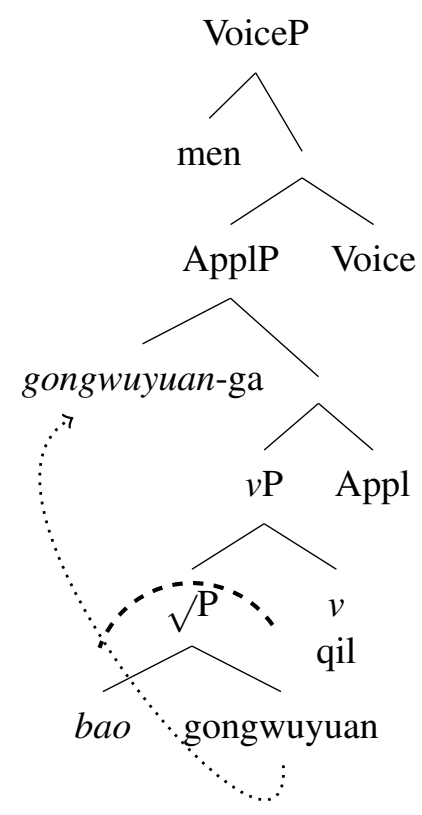

(44) Siz u-ga jidu qil-iwat-i-mu-siz.

1SG.FORM 3-DAT envy do-PROG-NPST-Q-2SG.FORM

"Do you envy her/him/them?"

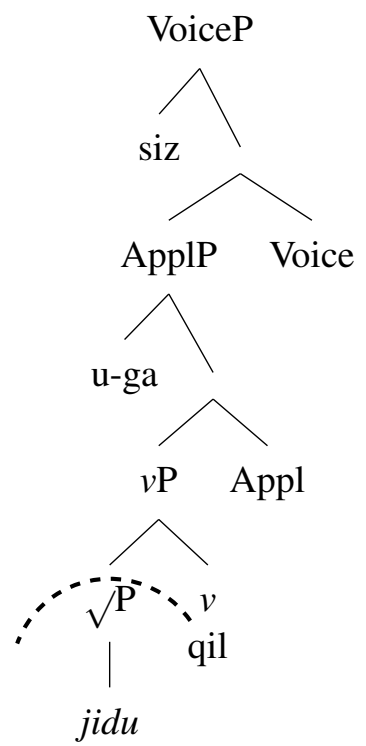

8. Apparent exceptions to the mixed verb case generalization.

8.1 Ablative to aCCUSATIVE. One apparent exception to the Mixed Verb Case Generalization involves Uyghur and Chinese verbs meaning 'to enjoy.' As shown in (46), the Uyghur verb huzurlan 'to enjoy' selects an ablative object. 
Ésil tamaq-lar-din huzur-la-n-iwat-i-miz.

Fine food-PL-ABL pleasure-VBLZ-PASS-PROG-NPST-1PL

'We're enjoying some fine food.' (uig)

However, the object of Chinese verb xiangshou 'to enjoy' receives accusative case in the mixed verb.
Ésil tamaq-lar-ni xiangshou qil-iwat-i-miz.
Fine food-PL-ACC enjoy do-PROG-NPST-1PL
'We're enjoying some fine food.'

One possible explanation for this pattern could be that the object in (46) is actually a partitive phrase headed by a covert accusative object (a la Kornfilt 1984 for Turkish). This analysis cannot apply to this Uyghur example. First, it is not possible to add an overt accusative object to (46).

*Ésil tamaq-lar-din ikki texse(-ni) huzur-la-n-iwat-i-miz. Fine food-PL-ABL two plate(-ACC) pleasure-VBLZ-PASS-PROG-NPST-1PL Intended: 'We're enjoying two plates of fine food.' (uig)

Second, when (46) is causativized, the causee obligatorily takes accusative case, suggesting that no accusative argument is present in (46).

Mektep biz-ni ésil tamaq-lar-din huzur-la-n-dur-di-0.

School 1PL-ACC fine food-PL-ABL pleasure-VBLZ-PASS-CAUS-PST-3

'The school had us enjoy fine foods.' (uig)

We take the crucial contrast between (46) and the examples presented in section 5 to be the idiosyncratically assigned case being ablative rather than dative. It may be that unlike dative case, ablative is truly assigned lexically or by a lower functional head that is lost in the mixed verb. Another significant difference between (46) and (47) is that the verb in the former shows passive morphology in the form of the $-(i) n$ suffix, while the light verb qil 'do' is used in the mixed verb. Lack of passive voice in the mixed verb may bleed assignment of ablative case.

8.2 Synonyms With Differing CASE Assignment. The other exceptional behavior found in our data is the availability of roughly synonymous verbs in Uyghur that differ in case assignment. Table 3 lists several Uyghur expressions whose meanings can be translated as 'to harm'. As the table shows, some Uyghur 'harm' verbs are narrower in their meaning than others, and they differ in the case assigned to their object.

\begin{tabular}{|c|c|c|c|}
\hline & Verb/expression & Object case & Domain of usage \\
\hline 1 & X-ga yamanliq qil & DAT & all \\
\hline 2 & X-ga ziyankeshlik qil & DAT & physical, emotional, financial \\
\hline 3 & X-ga ziyan sal & DAT & financial \\
\hline 4 & X-ni ziyangha uchrat & ACC & financial \\
\hline 5 & X-ni ziyanlandur & ACC & all \\
\hline
\end{tabular}

Table 3: Uyghur synonoms for 'to harm'

The Chinese verb hai is used to express 'to harm' in a mixed verb. Regardless of what sense of 
harm is being described, the object of harm always takes accusative case.

$\mathrm{U}$ men-ni hai-le qil-di-0.

3SG 1SG-ACC harm-LE do-PST-3

'(S)he harmed me.'

Logically, the closest translational equivalent to Chinese hai must be an Uyghur verb that also can convey any sense of 'harm'. As shown by table, two Uyghur verbs can be used to convey any type of harm: 1) X-ga yamanliq qil and 2) X-ni ziyanlandur. The object of the former is assigned dative case; the object of the latter is assigned accusative. However, there is reason to believe that yamanliq (as well as ziyankeshlik) is actually a nominal argument of qil 'do' receiving covert accusative case. First, -liq is a known nominalizing suffix (Tömür 2003, Tohti 2012). Second, it is possible for yamanliq to be overtly marked with accusative case when it is specific and/or fronted.

$$
\begin{array}{ll}
\text { Bu yaman-liq-ni kim qil-di-0? } \\
\text { DEM bad-NMLZ-ACC who do-PST-3 }
\end{array}
$$

'Who did this harm/bad thing?' (uig)

Expressions 1 and 2 are therefore double object constructions whose main verb is 'to do', and the harmed argument takes dative case due to the double accusative constraint in Uyghur. We can thus explain (50) as the Chinese verb hai matching its most equivalent Uyghur translation ziyanlandur, which selects an accusative internal argument.

8. Conclusion. This article has presented code switching data in which Chinese verbs appear to assign the same idiosyncratic dative case to their objects as their Uyghur translational equivalents. We have taken this data as evidence that what looks like idiosyncratic case is actually assigned by a functional projection (contra Woolford's 2006 complementary distribution generalization), and adopted an analysis in which certain roots trigger the presence of an applicative head which assigns dative case to its specifier. We hope to further flesh out an analysis which allows semantic information encoded in roots to condition case assignment by a functional head in future work.

\section{References}

Ahn, Byron Thomas. 2014. Giving reflexivity a voice: Twin reflexives in English. Doctoral dissertation, UCLA.

Aihemaiti, Kayisha'er. 2011. Wéiwú'ěryŭ xīnlì dòngcí de fēnlèi jí qí jùfă, yŭyì fēnxü. Journal of Kashgar Teachers College 32(1). 45-48.

Blume, Kerstin. 1998. A contrastive analysis of interaction verbs with dative complements. Linguistics 36(2). 253-280.

Chao, Yuen Ren. 1965. A grammar of spoken Chinese. Univ of California Press.

Chomsky, Noam. 1981. Lectures on government and binding. Dordrecht: Foris.

Chomsky, Noam. 1986. Knowledge of language. New York: Praeger.

Cuervo, Mar'1a Cristina. 2003. Datives at large. Doctoral dissertation, MIT.

Duanmu, San. 2007. The phonology of standard Chinese. Oxford University Press.

Duanmu, San. 2012. Word-length preferences in Chinese: a corpus study. Journal of East Asian Linguistics 21(1). 89-114.

Engesæth, Tarjei, Mahire Yakup \& Arienne Dwyer. 2010. Greetings from the Teklimkana: a 
Handbook of Modern Uyghur Volume 1. Lawrence: University of Kansas Scholarworks.

Feng, Shengli. 1995. Prosodic structure and prosodically constrained syntax in Chinese.

Doctoral dissertation, University of Pennsylvania.

Feng, Shengli. 2001. Minimal word in Mandarin Chinese. Ms., University of Kansas.

Halle, Morris and Alec Marantz. 1993. Distributed Morphology and the Pieces of Inflection. In

Ken Hale \& Samuel Jay Keyser (eds.), The View from Building 20. MIT Press.

Harada, Shin-Ichi. 1973. Counter equi NP deletion. Annual Bulletin 7. 113-147. Research

Institute of Logopedics and Phoniatrics, University of Tokyo.

Harley, Heidi. 2014. On the identity of roots. Theoretical linguistics, 40(3-4), pp.225-276.

Kahnemuyipour, Arsalan. 2009. The syntax of sentential stress. Oxford: Oxford University Press.

Klein, Wolfgang, Ping Li, and Hemriette Hendriks. 2000. Aspect and assertion in Mandarin Chinese. Natural Language \& Linguistic Theory 18(4). 723-770.

Kornfilt, Jaklin. 1984. Case marking, agreement, and empty categories in Turkish. Doctoral dissertation, Harvard University.

Lakshmanan, Usha, Osmer Balam, and Tej Bhatia. 2016. Introducing the special issue: Mixed verbs and linguistic creativity in bi/multilingual communities. Languages 1(2). 11.

Li, Charles and Sandra Thompson. 1981. A functional reference grammar of Mandarin Chinese. Berkeley, CA: University of California Press.

MacSwan, Jeff. 2014. Programs and proposals in codeswitching research: Unconstraining theories of bilingual language mixing. In Jeff MacSwan (ed.), Grammatical theory and bilingual codeswitching. 1-33. Cambridge, MA: MIT Press.

Marantz, Alec. 1991. Case and licensing. Eastern States Conference on Linguistics (ESCOL) 8. 234-253.

Merchant, Jason. 2018. Roots don't select, categorial heads do: Lexical-selection of PPs may vary by category. Ms., University of Chicago.

Shih, Chi Lin. 1986. The prosodic domain of tone sandhi in Chinese. Doctoral dissertation, University of California, San Diego.

Shim, Ji. 2016. Mixed verbs in code-switching: The syntax of light verbs. Languages 1(1). 8.

Sugar, Alexander. 2017. Mandarin Chinese verbs as verbal Items in Uyghur mixed verbs. Languages, 2(1), p.1.

Sugar, Alexander and Zaoreguli Abulimiti. 2018. Causativity Preservation in Uyghur-Chinese Light Verb Constructions. Presentation at the Beijing Argument Structure and Event Structure Workshop, Beijing Institute of Technology, 10/27/2018.

Tohti, Litip. 2012. Xiàndài wéiwú'ěryŭ cānkăo yŭfă. Beijing: China Social Sciences Press.

Tömür, Hamit. 2003. Modern Uyghur Grammar: Morphology. Trans. Anne Lee. Istanbul, Turkey: Yildiz.

Wohlgemuth, Jan. 2009. A typology of verbal borrowings (Vol. 211). Walter de Gruyter.

Woolford, Ellen. 2006. Lexical case, inherent case, and argument structure. Linguistic inquiry, 37(1), pp.111-130.

Zaoreguli Abulimiti. 2009. Cóng shùnyìng lìlùn yánjiū wéiwú’ĕrzú dàxuéshēng kŏuyŭzhōng de wéihàn yŭmă zhuănhuàn. MA Thesis, Xinjiang Normal University.

Zaoreguli Abulimiti and Alexander Sugar. Under review. Le as a Prosodic Filler in Uyghur-Chinese Mixed Verbs. 